\title{
The prevalence of asthma in children: a reversing trend
}

\author{
C.P. van Schayck* and H.A. Smit ${ }^{\#}$
}

\begin{abstract}
In several countries it has been observed that there has been no further increase in the prevalence of asthma. This study aimed to look at asthma prevalence in children during the past 15-30 years in The Netherlands.
\end{abstract}

Both general practice registration (Continuous Morbidity Registration, Nijmegen) and surveys of the public health service in Limburg (Southern parts of the Netherlands) were used for this purpose.

The general practice registration showed that after a five-fold increase in asthma prevalence during the 1980s and 1990s a downward trend seemed to occur around the turn of the century. The public health service confirms a clear decrease in wheezing and dyspnoea in children during the late 1990s. Thus far, there has been no satisfactory explanation for this observation.

\section{KEYWORDS: Asthma, children, prevalence}

ince the 1980s a strong increase in the prevalence of asthma has taken place [1, 2]. In several countries, an increase in the prevalence of asthma has been reported on the basis of several morbidity indicators, such as hospital admissions [3], general practitioner (GP) diagnosis [4] and asthma symptoms, as well as objective features of asthma, such as atopy or hyperresponsiveness $[5,6]$. The average increase in asthma symptoms was $\sim 5 \%$ per year [7]. The increase may have been caused by increasing awareness in doctors and patients, but there is general consensus that at least part of the increased registered morbidity is attributable to an actual rise in the number of asthma cases.

The general practice registrations provide a fair reflection of the morbidity presented to a GP. However, these do not necessarily represent the total morbidity in the open population as diseases are often under-reported. The advantage of epidemiological population studies is that these studies use standardised methods to measure aspects of asthma morbidity. However, the disadvantage is that these studies are often based on questionnaires, without clinical interpretation of the symptoms by a doctor. In order to obtain a good impression of the actual prevalence data sources contribute relevant information.

Recently, the first publications have appeared that indicate that in several countries, no further increase (and possibly even a decrease) is being observed in the prevalence of asthma among children [8-15]. Thus far, it is unclear what might have caused this recent change [16]. In the present study, recent trends in asthma morbidity in the Netherlands from GP registrations and repeated cross-sectional surveys are reported.

\section{REVERSING THE TREND OF ASTHMA PREVALENCE IN CHILDREN IN THE NETHERLANDS}

Data from the general practice registrations of the Dutch Nijmegen Continuous Morbidity Registration (CMR; the Netherlands) have shown a steep rise in asthma prevalence since the 1980s [17]. The CMR recording is based on the Dutch healthcare system, where all patients are registered with a GP and all access to care is via the physician [18]. The CMR consists of 12,000 subjects and began in 1967. In the database, all morbidity presented in general practice is recorded in a standardised way, and the diagnosis is based on the International Classification of Health Problems in Primary Care [19]. Asthma is defined as recurrent episodes of acute bronchial obstruction with either pulmonary function tests showing variable obstruction relieved by bronchodilators, or the presence of respiratory symptoms, such as wheeze, dry cough and prolonged expiratory phase. The increase in

\section{AFFILIATIONS}

${ }^{*}$ Dept of General Practice, Caphri Research Institute, Maastricht University, and

${ }^{\text {\#} C e n t e r ~ f o r ~ P r e v e n t i o n ~ a n d ~ H e a l t h ~}$ Services Research, National Institute of Public Health, Bilthoven, The Netherlands.

CORRESPONDENCE

C.P. van Schayck Dept of General Practice University Maastricht P.0. Box 616 6200 MD Maastricht The Netherlands Fax: 31433619344 E-mail: onno.vanschayck@hag.unimaas.nl

Received:

February 212005

Accepted after revision: June 152005 
asthma prevalence in the CMR was greatest in children and lower in older age groups. The prevalence of 10 per 1,000 children in 1983 had increased at least five-fold in 1999, making asthma one of the diseases that have increased most during the past $10 \mathrm{yrs}$. It is striking, however, that a recent downward trend seems to have set in around the late 1990s, especially among children (fig. 1).

Furthermore, recent data from repeated cross-sectional surveys suggest a possible recent declining trend in asthma prevalence among children in the southern part of the Dutch province of Limburg (the Netherlands). Since 1989, the regional public health service of this area has investigated the prevalence of respiratory complaints every 4 yrs. As the survey was combined with normal periodic medical examination, $>95 \%$ of the invited children participated. The studies in 1989, 1993, 1997 and 2001 included 1,794, 1,526, 1,670 and 1,102 children aged 8-9 yrs, respectively. All four surveys used the same questionnaire, in which questions were asked about coughing, productive cough, chest wheezing, shortness of breath and medication relating to respiratory complaints over the past 12 months. Age and sex distributions were similar in each of the four successive surveys, so there appears to have been no selection bias in the study population [20]. It was striking that the presence of one or more respiratory complaints shows a clear and steady decline from $17.4 \%$ in 1989 to $13.5 \%$ in 2001 , whereas the use of (bronchodilator and inhaled steroid) medication by wheezing children has clearly increased from almost $40 \%$ in 1989 to $56 \%$ in 2001 (fig. 2).

\section{DISCUSSION}

These data suggest that in the Netherlands, after an initial increase, the prevalence of respiratory complaints in children is now stabilising or even declining. The causes of this trend can only be speculated. It has been suggested that the underlying cause of the increase in asthma cases could be due to changes towards a western lifestyle [21-23]. These lifestyle factors would play a dominant role just before and after birth, which could be the explanation as to why an increase is observed especially in young children [24]. Interestingly, children who

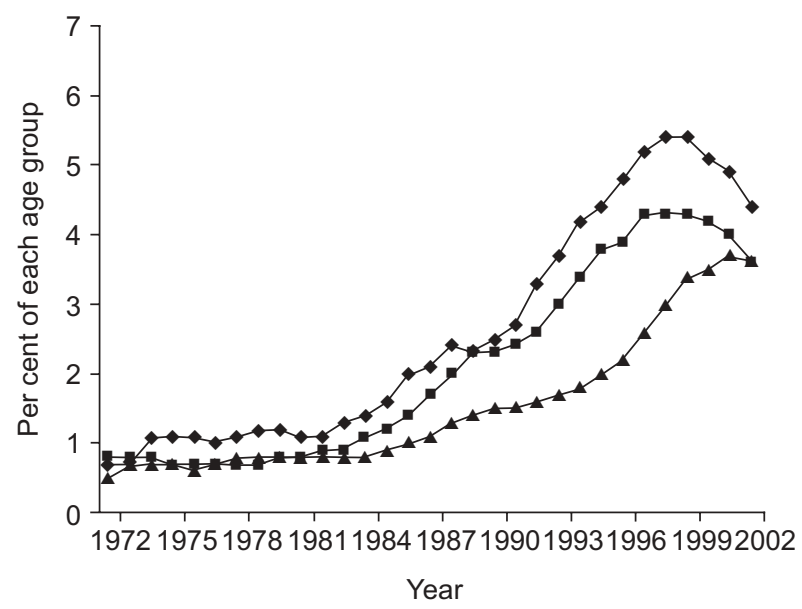

FIGURE 1. Asthma prevalence during 1972-2002 (3-yr progressive mean) for subjects aged $<45$ yrs. $\bullet$ : aged 0-14 yrs; $\mathbf{\square}$ : aged 15-24 yrs; $\mathbf{\Lambda}$ : aged 25-44 yrs. Standardised for the population of the Netherlands in $1990[17,18]$.

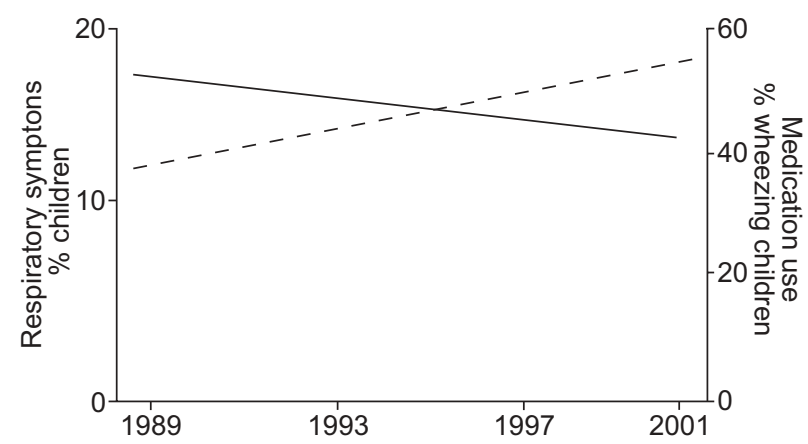

FIGURE 2. Percentage of children in Limburg, the Netherlands, with one or more respiratory symptom (-), and percentage of wheezing children with bronchodilator and inhaled steroid medication (- - ) [20].

were born after the re-unification in former East-Germany showed an increase in asthma prevalence [25]. However, other explanations, such as (confounding) behaviour by parents, might also contribute to these observations [26]. Moreover, it seems unlikely that the recent observed decline would be due to a stabilisation in a western lifestyle. Besides, it cannot be explained that the increase in childhood asthma prevalence mainly took place in the 1980s and 1990s, while the change towards a western lifestyle with an increased hygiene started years before that period. It is not unlikely that a prevalence plateau of all genetically predisposed children has been reached, i.e. that all children with genetic predisposition become asthmatic, due to relevant exposure. In addition, these children were detected earlier because of increased alertness and improved diagnostics.

It seems more likely that a possible decline in asthma prevalence is related to improved diagnostics followed by correct treatment (fig. 2). It is obvious that the observed changes in symptoms and medication use are not necessarily causally related, but it is not unlikely that these factors are associated. This suggestion is further strengthened by the observed clear decrease in wheezing and shortness of breath between 1997 and 2001 [20]. This period coincides with the publication by the Dutch College of General Practitioners of the guidelines for the diagnosis and treatment of childhood asthma [27]. These guidelines underline the importance of early and adequate treatment with inhaled corticosteroids. Interestingly, in England [28] and the USA [12] no increase was found in the number of GP visits for asthma complaints in the 1990s. This finding was probably directly related to improved asthma management [28]. In Finland, "primary care teams" were established and trained, resulting in a $75 \%$ increase in the use of inhaled corticosteroids, accompanied by an $80 \%$ decrease in hospitalisation and mortality due to asthma [29]. In the Netherlands, mortality as a result of asthma among patients < 35 yrs of age has also shown a striking, sharp decrease in the early 1990s (fig. 3), which is likely to be related to improved treatment.

\section{Conclusion}

In conclusion, it can be determined that in the Netherlands a steep rise in the prevalence of asthma since the 1980s is being followed by a levelling off or a decreasing trend, especially among children. Given that a clear explanation for the 


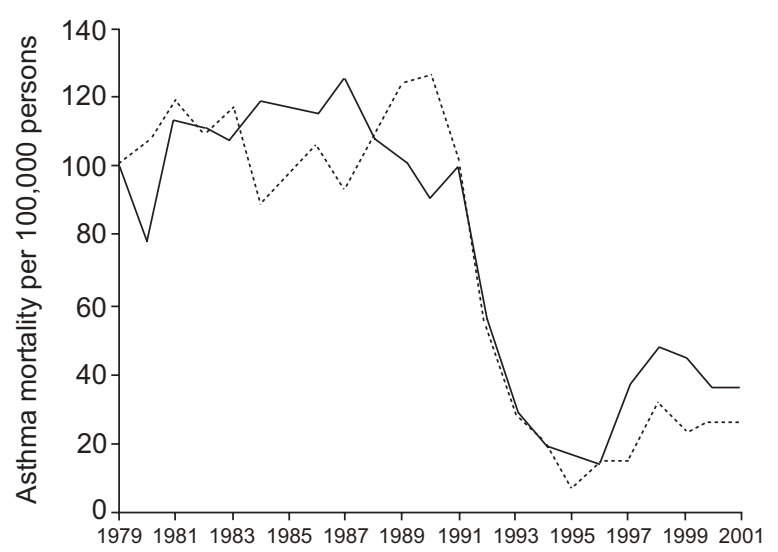

FIGURE 3. Asthma mortality among males (- - ) and females (-) aged 5-34 yrs in the Netherlands in the period 1979-2001 (per 100,000 people).

increasing trends has still not been established, it is too early to draw conclusions on the newly developing reversing trend.

\section{ACKNOWLEDGEMENTS}

The authors would like to thank R. Gijsen and H. Van den Hoogen for making data of the Continuous Morbidity Registration of Nijmegen University (The Netherlands) available.

\section{REFERENCES}

1 van Schayck CP, van der Heijden FMMA, van den Boom G, Tirimanna PRS, van Herwaarden CLA. Underdiagnosis of asthma: is the doctor or the patient to blame? The DIMCA project. Thorax 2000; 55: 562-565.

2 Kuehni CE, Davis A, Brooke AM, Silverman M. Are all wheezing disorders in very young (preschool) children increasing in prevalence? Lancet 2001; 357: 1821-1825.

3 Hyndman SJ, Williams DR, Merrill SL, Lipscombe JM, Palmer CR. Rates of admission to hospital for asthma. BMJ 2004; 308: 1596-1600.

4 Fleming DM, Crombie DL. Prevalence of asthma and hay fever in England and Wales. BMJ (Clin Res Ed) 1987; 294: 279-283.

5 Downs SH, Marks GB, Sporik R, Belosouva GE, Car NG, Peat JK. Continued increase in the prevalence of asthma and atopy. Arch Dis Child 2001; 84: 20-23.

6 Linneberg A, Nielsen NH, Madsen F, Frolund L, Dirksen A, Jorgensen $T$. Increasing prevalence of specific $\operatorname{IgE}$ to aeroallergens in an adult population: two cross-sectional surveys 8 years apart: the Copenhagen Allergy Study. J Allergy Clin Immunol 2000; 106: 247-252.

7 Burney P. The changing prevalence of asthma? Thorax 2002; 57: Suppl. 2, II36-II39.

8 Braun-Fahrlander C, Gassner M, Grize L, et al. No further increase in asthma, hay fever and atopic sensitisation in adolescents in Switzerland. Eur Respir J 2004; 23: 407-413.

9 Toelle BG, Ng K, Belousova E, Salome CM, Peat JK, Marks GB. Prevalence of asthma and allergy in schoolchildren in Belmont, Australia: three cross-sectional surveys over 20 years. BMJ 2004; 328: 386-387.
10 Wong GWK, Leung TF, Ko FWS, et al. Declining asthma prevalence in Hong Kong Chinese schoolchildren. Clin Exp Allergy 2004; 34: 1550-1555.

11 Ronchetti R, Villa MP, Barreto $\mathrm{M}$, et al. Is the increase in childhood asthma coming to an end? Findings from three surveys of schoolchildren in Rome, Italy. Eur Respir J 2001; 17: 881-886.

12 Fleming DM, Sunderland R, Cross KW, Ross AM. Declining incidence of episodes of asthma: a study of trends in new episodes presenting to general practitioners in the period 1989-1998. Thorax 2000; 55: 657-661.

13 Hong S-J, Lee M-S, Sohn MH, et al. Self-reported prevalence and risk factors of asthma among Korean adolescents: 5-year follow-up study, 1995-2000. Clin Exp Allergy 2004; 34: 1556-1562.

14 Anderson HR, Ruggles R, Strachan DP, et al. Trends in prevalence of symptoms of asthma, hay fever, and eczema in 12-14 year olds in the British Isles, 1995-2002: questionnaire survey. BMJ 2004; 328: 1052-1053.

15 Devenny A, Wassall $\mathrm{H}$, Ninan $\mathrm{T}$, et al. Respiratory symptoms and atopy in children in Aberdeen: questionnaire studies of a defined school population repeated over 35 years. BMJ 2004; 329: 489-490.

16 Toelle BG, Marks GB. The ebb and flow of asthma. Thorax 2005; 60: 87-88.

17 Boezen HM, Postma DS, Smit HA, Gijsen R, Poos MJJC. Neemt het aantal mensen met astma en COPD toe of af? [Does the number of patients with asthma or COPD increase or decrease?] In: Nijmegen CMR, Volksgezondheid Toekomst Verkenningen, Nationaal Kompas Volksgezondheid. Bilthoven, RIVM, 2004. www.rivm.nl/vtv/data/kompas/gezondheidstoestand/ ziekte/cara/cara_trend.htm

18 van Weel C. Validating long-term morbidity recording. J Epidemiol Comm Health 1995; 49: 29-32.

19 WONCA. An international glossary for primary care. In: Classification Committee of WONCA in collaboration with the WHO. International Classification of Health Problems in Primary Care-2-defined. 3rd Edn. London, Oxford University Press, 1983.

20 Mommers M, Gielkens-Sijstermans C, Swaen GMH, van Schayck CP. Trends in the prevalence of respiratory symptoms and treatment in Dutch children over a 12-year period: results from the fourth consecutive survey. Thorax 2005; 60: 97-99.

21 Matricardi PM. Prevalence of atopy and asthma in eastern versus western Europe: why the difference? Ann Allergy Asthma Immunol 2001; 87: Suppl. 3, 21-27.

22 Nowak D, Heinrich J, Jorres R, et al. Prevalence of respiratory symptoms, bronchial hyperresponsiveness and atopy among adults: west and east Germany. Eur Respir J 1996; 9: 2541-2552.

23 Cook DG, Strachan DP. Health effects of passive smoking. 3. Parental smoking and prevalence of respiratory symptoms and asthma in school age children. Thorax 1997; 52: 1081-1094.

24 Heinrich J, Hoelscher B, Frye C, Meyer I, Wijst M, Wichmann HE. Trends in prevalence of atopic diseases and allergic sensitization in children in Eastern Germany. Eur Respir J 2002; 19: 1040-1046. 
25 von Mutius E. The rising trends in asthma and allergic disease. Clin Exp Allergy 1998; 28: Suppl. 5, 45-51.

26 van Schayck CP, Knottnerus JA. Can the hygiene hypothesis be explained by confounding by behaviour and health? J Clin Epid 2004; 57: 435-437.

27 Dirksen WJ, Geijer RM, De Haan M, De Koning G, Flikweert S, Kolnaar B. NHG-Standaard Astma bij Kinderen (eerste herziening). [Guidelines of the Dutch
College of General Practitioners: asthma in children]. Huisarts Wet 1998; 41: 130-143.

28 Stafford RS, Ma J, Finkelstein SN, Haver K, Cockburn I. National trends in asthma visits and asthma pharmacotherapy, 1978-2002. J Allergy Clin Immunol 2003; 111: 729-735.

29 Haahtela T, Klaukka T, Koskela K, Erhola M, Laitinen LA. Asthma programme in Finland: a community problem needs community solutions. Thorax 2001; 56: 806-814. 